\title{
METОАЫ ИССАЕАОВАНИЙ
}

УДК 617-001-053.2-07

\section{ПАНСОНОСКОПИЯ ПРИ ПОАИТРАВМЕ (НОВАЯ МЕАИЦИНСКАЯ ТЕХНОАОГИЯ)}

\author{
(С Иова А. С., Крюкова И. А., Иова Д. А.
}

ГБОУ ВПО «СЗГМУ им. И. И. Мечникова» Минздрава России, Санкт-Петербург ФГБУ «НИДОИ им. Г. И. Турнера» Минздрава России, Санкт-Петербург

Статья посвящена актуальной проблеме современной травматологии - улучшению оказания медицинской помощи пациентам с политравмой. Представлена новая технология "пансоноскопия", которая является минимально инвазивным и широкодоступным способом быстрой визуализации «всего тела» пациента в любых медицинских условиях. Она позволяет в режиме реального времени с помощью портативных ультразвуковых аппаратов выявлять наиболее частые и опасные травматические повреждения (краниальные, торакальные, абдоминальные, скелетные и др.). Принципиально новым является: обеспечение визуализации внутричерепных повреждений, возможность проведения исследования самим клиницистом (травматологом, хирургом, нейрохирургом, неврологом), а также возможность телемедицинского консилиума с экспертами (специалистами ультразвуковой диагностики). Эта технология предназначена для широкого круга врачей, оказывающих медицинскую помощь пациентам с политравмой.

Ключевые слова: транскраниальная ультрасонография, ультрасонография всего тела, ургентная сонография, пансоноскопия, политравма, сочетанная черепно-мозговая травма у детей и взрослых, FAST-протокол.

\section{Введение}

При политравме необходимо в кратчайшие сроки уточнить характер и локализацию повреждений. Чем раньше установлен диагноз, тем больше шансов на благоприятный исход [1-3]. Однако именно диагностический этап оказания медицинской помощи в условиях острого дефицита времени и информации о пациенте представляет наибольшие трудности. Проведение только клинического обследования не может обеспечить качественную и своевременную диагностику повреждений, особенно у «критических» больных, находящихся без сознания и самостоятельного дыхания. В этих случаях особое значение имеют технологии медицинской визуализации (интраскопии) $[3,4,10-12,15]$.

Экспертной визуализационной технологией при политравме является компьютерная томография (КТ), которая обладает высокой чувствительностью при травматических повреждениях головного мозга, внутренних органов и костей. В ряде случаев для уточнения диагноза применяется магнитно-резонансная томография (МРТ). В последние годы появились такие понятия, как «КТ и МРТ всего тела» (“Whole-body CT”) [10, 15, 20]. «КТ всего тела» позволяет практически одномоментно выявлять интракраниальные, торакоабдоминальные, сосудистые и костные повреждения. Однако эта технология имеет ряд недостатков, которые особенно остро проявляются в условиях оказания медицинской помощи пациентам, находящимся в критическом состоянии. Эти больные нетранспортабельны и гемодинамически нестабильны. Основные недостатки КТ: невозможность применения на догоспитальном этапе, необходимость транспортировки пациента в КТ-зал, невозможность выполнения КТ параллельно с реанимационными мероприятиями, высокая стоимость, а также наличие ионизирующей радиации. Последний недостаток имеет особое значение при обследовании детей и беременных женщин. Появление мобильных КТ и МРТ- комплексов позволяет лишь частично устранить перечисленные недостатки.

Ультрасонография (УС) является признанной скрининговой технологией. Ее возможности и перспективы бесспорны, особенно в травматологии. Портативность ультразвуковой техники позволяет производить исследо- 
вания «у постели больного» и «в любых условиях» (от полевых до госпитальных), даже параллельно с реанимационными мероприятиями $[3,4,9,12-14,22,25,26]$.

Впервые использование УС при травме живота было описано J. K. Kristensen в 1971 г. [23]. Однако, как показала практика, при повреждении паренхиматозных органов УС обладает низкой чувствительностью (до $41 \%$ ) и часто не позволяет обнаружить разрывы полых органов. В то же время УС обладает высокой чувствительностью и специфичностью при выявлении свободной жидкости. В 1995 г. G. S. Rozycki [et al.] предложили для обозначения протокола УС, направленного на поиск крови в перитонеальной и перикардиальной полостях, использовать термин «FAST» (Focused Assessment with Sonography for Trauma) [26]. В дальнейшем, в 2004 г., A. W. Kirkpatrick [et al.] предложили расширенный FAST-протокол (extended FAST), в который был добавлен поиск пневмоторакса и гемоторакса [24].
C 2008 г. FAST-протокол включен в программу поддержания жизнеобеспечения при травме - ATLS (Advanced Trauma Life Support) и представляет собой краткое и быстрое (в течение 3-3,5 мин.) ультразвуковое исследование, направленное на поиск крови в перитонеальной, плевральной и перикардиальной полостях (табл. 1). FAST-протокол сегодня применяется во многих странах у пациентов с политравмой $[12,21,22,24-26]$. Применение FAST-протокола помогает быстро сортировать пациентов: а) при положительном FAST и нестабильной гемодинамике необходима экстренная хирургическая помощь; б) при положительном FAST и стабильной гемодинамике целесообразна более детальная диагностика повреждений (УС, КТ или др.); в) отрицательный FAST не позволяет исключить значимые повреждения внутренних органов и сосудов, поэтому такие пациенты нуждаются в дообследовании и мониторинге $[21,22,25]$.

Таблица 1

Особенности общепринятого FAST-протокола

\begin{tabular}{|c|c|c|}
\hline Точки сканирования & Области сканирования & Задачи \\
\hline & $\begin{array}{l}\text { Правый верхний ква- } \\
\text { дрант живота }\end{array}$ & $\begin{array}{l}\text { Поиск жидкости в гепаторенальном кармане } \\
\text { (кармане Морисона), вокруг печени, в правой } \\
\text { плевральной полости }\end{array}$ \\
\hline & $\begin{array}{l}\text { Левый верхний ква- } \\
\text { дрант живота }\end{array}$ & $\begin{array}{l}\text { Поиск жидкости в спленоренальном карма- } \\
\text { не, левом поддиафрагмальном пространстве, } \\
\text { в левой плевральной полости }\end{array}$ \\
\hline & Субкостальная область & Поиск жидкости в перикардиальной полости \\
\hline & Надлобковая область & Поиск жидкости в полости малого таза \\
\hline & $\begin{array}{l}\text { Верхняя часть грудной } \\
\text { клетки }\end{array}$ & Поиск пневмоторакса \\
\hline
\end{tabular}

На сегодняшний день УС позволяет визуализировать практически все внутренние органы и полости, опорно-двигательный аппарат, сосуды и периферические нервы. Принципиальным недостатком «УС всего тела» (в том числе и FAST-протокола) по отношению к «КТ всего тела» и «МРТ всего тела» является невозможность визуализации внутричерепного пространства. Этот недостаток является очень серьезным, поскольку черепно-мозговая травма (ЧМТ) регистрируется у $70 \%$ пострадавших с политравмой. Именно она часто представляет собой наибольшую угрозу для жизни пациента и требует проведения срочных специальных мероприятий.
Даже новорожденные и младенцы с открытым передним родничком не являются исключением, поскольку стандартная чрезродничковая УС визуализирует лишь часть внутричерепного пространства. Причем чем меньше родничок, тем больше риск опасной врачебной ошибки $[9,20]$.

Появление термина «пансоноскопия» стало возможным лишь после разработки методики ультразвукового исследования внутричерепного пространства через чешую височной кости - «транскраниальной ультрасонографии» (ТУС) $[5-7,16]$. В 2011 г. в России «Пансоноскопия в условиях неотложной медицины» была официально утверждена как новая медицинская технология $[8,9]$. 


\section{Цель настоящей работы}

Ознакомить широкий круг практических врачей, оказывающих медицинскую помощь при политравме, с возможностями ультрасонографии в экспресс-диагностике и минимально инвазивном мониторинге травматических внутричерепных повреждений.

\section{Общая характеристика новой меАицинской технологии}

Пансоноскопия (ПС) - это технология минимально инвазивной визуализации «всего тела» человека с помощью ультразвука в любых медицинских условиях.

Трактовка термина: а) «пан...» (греч. «рап» - все) - приставка, указывающая на полный охват чего-либо и в слове «пансоноскопия» предполагает возможность обследования всего тела пациента, всех возрастов и на всех этапах оказания медицинской помощи (от первичной сортировки на месте катастрофы с большим количеством пострадавших до интраскопического сопровождения хирургического вмешательства в центрах оказания высокотехнологичной медицинской помощи); б) «...соно...» (лат. «sonus» - звук); в) «...скопия» (греч. «skopeo» - смотрю) - осмотр в режиме реального времени.

В зависимости от целей выделяют профилактическую и ургентную ПС, которые отличаются друг от друга объемом исследования и необходимым уровнем подготовки врача-исследователя. Настоящая работа посвящена ургентной ПС, которую при необходимости может выполнять врач-клиницист, прошедший специальную подготовку (рис. 1).

Инновационным в этой технологии является обеспечение возможности визуализации внутричерепного пространства за счет ТУС. Поэтому ПС включает в себя две основные части - краниальную и экстракраниальную УС, которые могут выполняться в виде краткого или расширенного протоколов (рис. 2).

Протоколы краниальной УС: а) краткий ТУС через височные точки; б) расширенный - у пациентов после закрытия переднего родничка проводится ТУС через височные и дополнительные точки, а при открытом родничке - транскраниально-чрезродничковая УС (ТЧУС).

Протоколы экстракраниальной УС: а) краткий - соответствует существующему FASTпротоколу и направлен на исключение гемоторакса, гемоперитонеума, гемоперикарда, пневмоторакса; б) расширенный (по показаниям) - полноценное ультразвуковое исследование органов шеи, грудной клетки, брюшной полости и забрюшинного пространства, малого таза, мягких тканей, костей, сосудов и др.

ТУС позволяет визуализировать внутричерепное пространство с помощью ультразвукового сканирования в В-режиме, осуществляемого через кости черепа в точках наибольшей их ультразвуковой проницаемости. Основное значение имеет сканирование через височные точки (краткий протокол ТУС). Пространственная ориентация получаемых горизонтальных плоскостей сканирования представлена на рис. 3. Для этого необходим датчик секторного сканирования (частотой 3,5 МГц для детей младше 1 года или частотой 2 МГц для детей старше 1 года и взрослых). Оптимальными являются секторные мультичастотные датчики с фазированной решеткой 4-2 МГц.

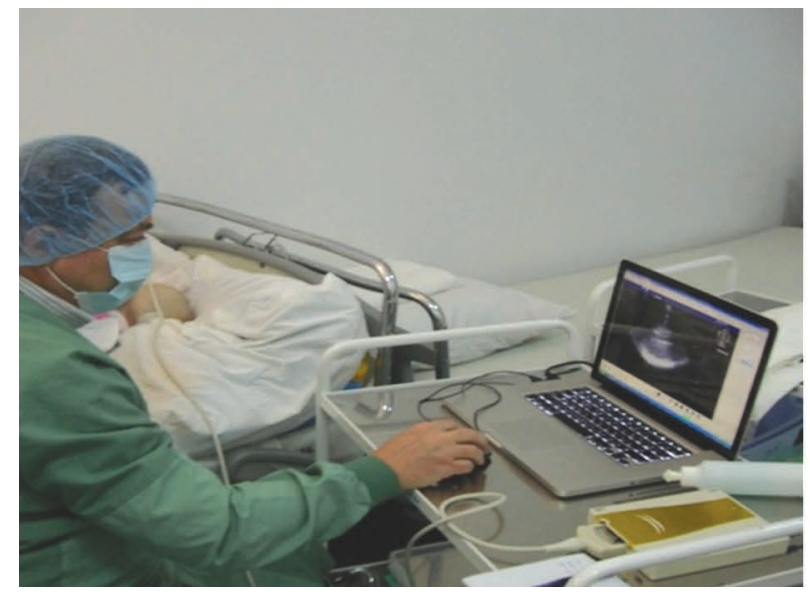

$a$

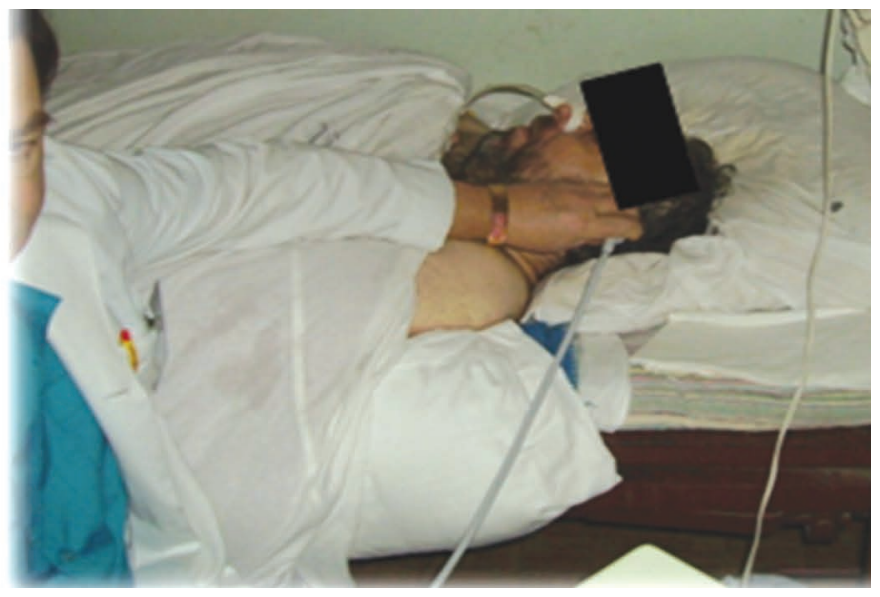

6

Рис. 1. Проведение транскраниальной ультрасонографии нейрохирургом у постели больного ребенка (a) и взрослого пациента (б) 


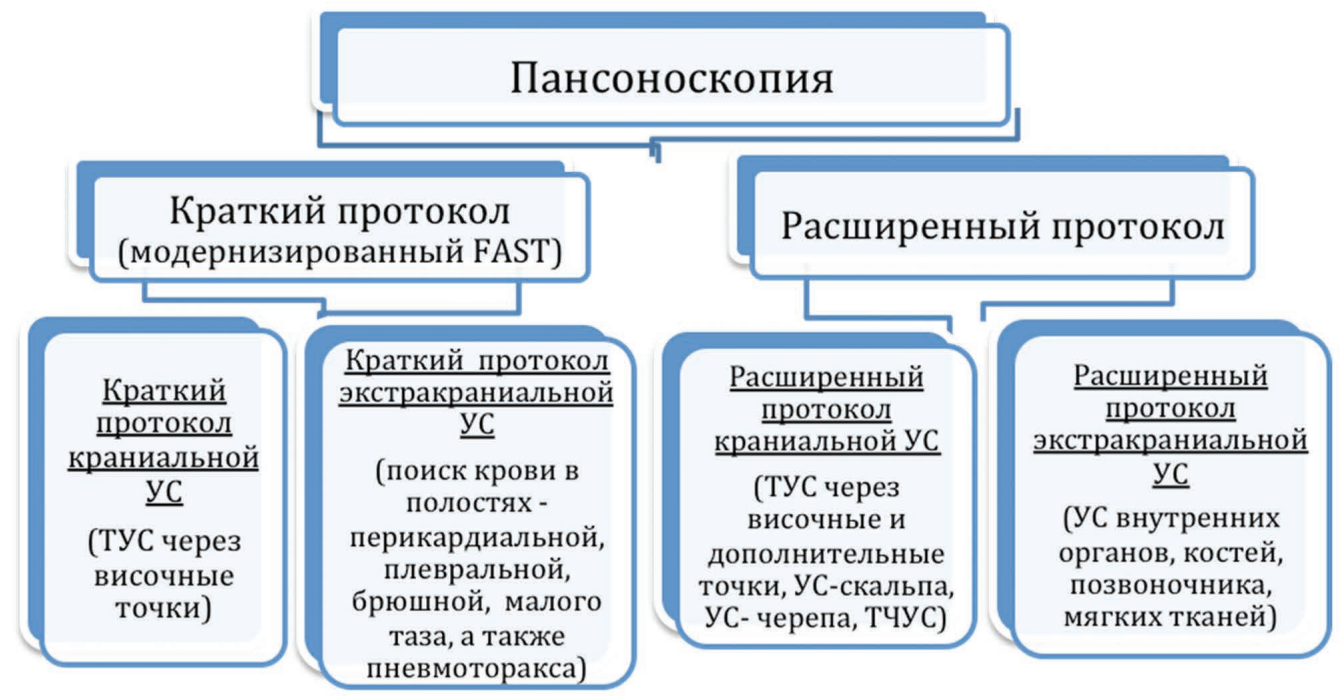

Рис. 2. Общая характеристика протоколов пансоноскопии

В табл. 2 представлены особенности проведения ТУС по краткому протоколу (основные режимы сканирования и их внутричерепные маркеры, последовательность получения изображений, стандартная сонометрия). На рис. 4 представлена верификация элементов эхо-архитектоники стандартных горизонтальных плоскостей сканирования при ТУС. У детей до 10 лет используют дополнительные точки (затылочные, срединно-сагиттальную точку bregma). Методика проведения ТУС подробно описана в специальном учебном пособии $[6,7]$.

таблица 2

Общая характеристика основных плоскостей сканирования при кратком протоколе ТУС

\begin{tabular}{|c|c|c|}
\hline № & Режим & Внутричерепные маркеры и измерения \\
\hline 1 & $\mathrm{TH}_{0}(\mathrm{~s})$ & $\begin{array}{l}\text { Средний мозг, цистерны основания мозга с тремя боковыми и тремя передними выворотами. } \\
\text { Измерение ширины и глубины залегания височного рога левого бокового желудочка }\end{array}$ \\
\hline 2 & $\mathrm{TH}_{1}(\mathrm{~s})$ & Третий желудочек, шишковидное тело. Измерение ширины третьего желудочка и дистанции Ms. \\
\hline 3 & $\mathrm{TH}_{2}(\mathrm{~s})$ & $\begin{array}{l}\text { Тела боковых желудочков и сосудистые сплетения, прилегающие друг к другу в области про- } \\
\text { зрачной перегородки. Измерение ширины правого бокового желудочка (Vld) }\end{array}$ \\
\hline 4 & $\mathrm{TH}_{0}(\mathrm{~d})$ & $\begin{array}{l}\text { Аналогично } \mathrm{TH}_{0}(\mathrm{~s}) \text {. Измерение ширины и глубины залегания височного рога правого боково- } \\
\text { го желудочка }\end{array}$ \\
\hline 5 & $\mathrm{TH}_{1}(\mathrm{~d})$ & Аналогично $\mathrm{TH}_{1}$ (s). Измерение дистанции $\mathrm{Md}$ \\
\hline 6 & $\mathrm{TH}_{2}(\mathrm{~d})$ & Аналогично $\mathrm{TH}_{2}$ (s). Измерение ширины левого бокового желудочка (Vls) \\
\hline
\end{tabular}

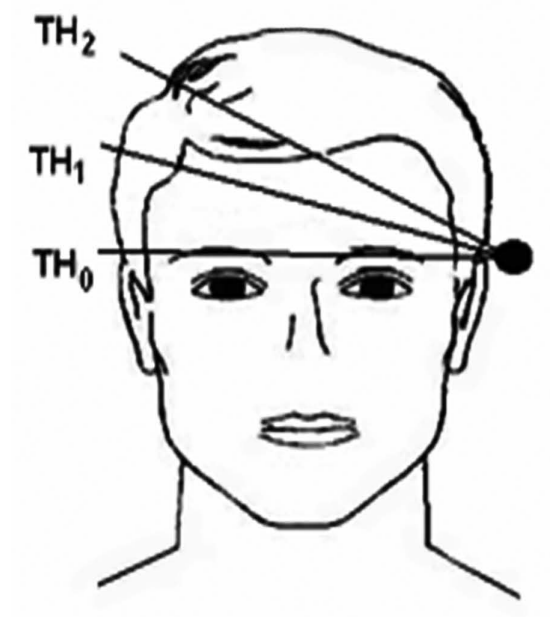

$a$

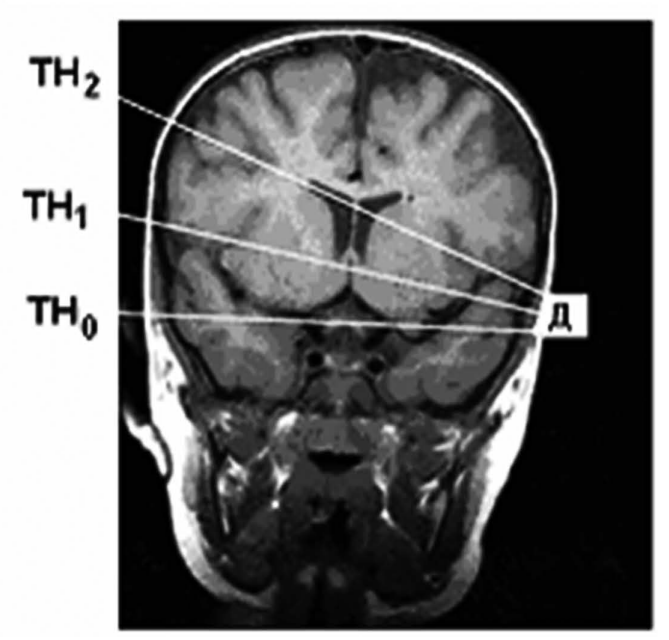

6

Рис. 3. Схема основных плоскостей сканирования (a) и их пространственная ориентация по данным МРТ (б) при транскраниальной ультрасонографии 


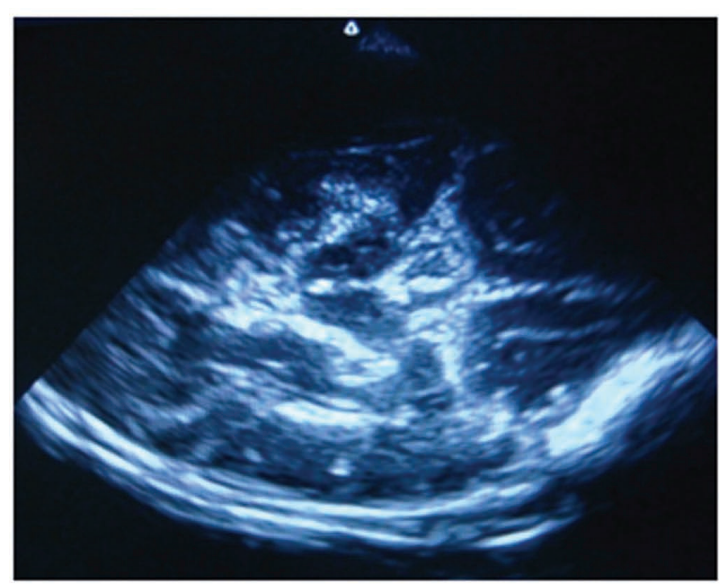

A

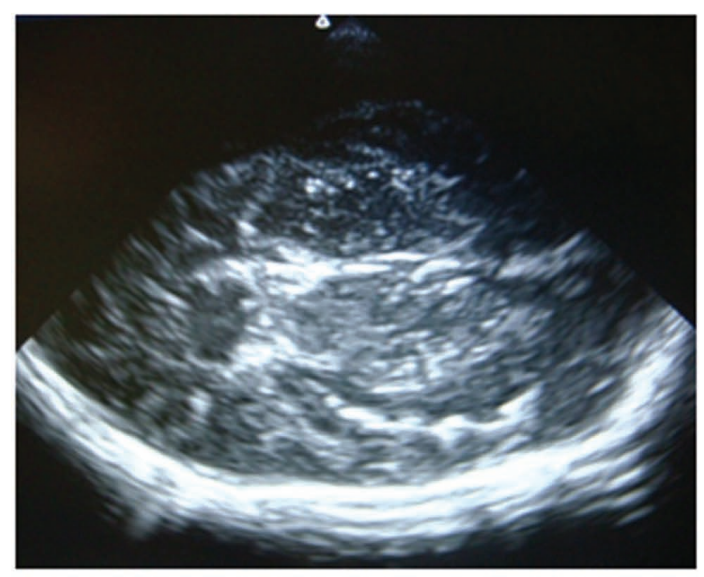

$\mathrm{B}$

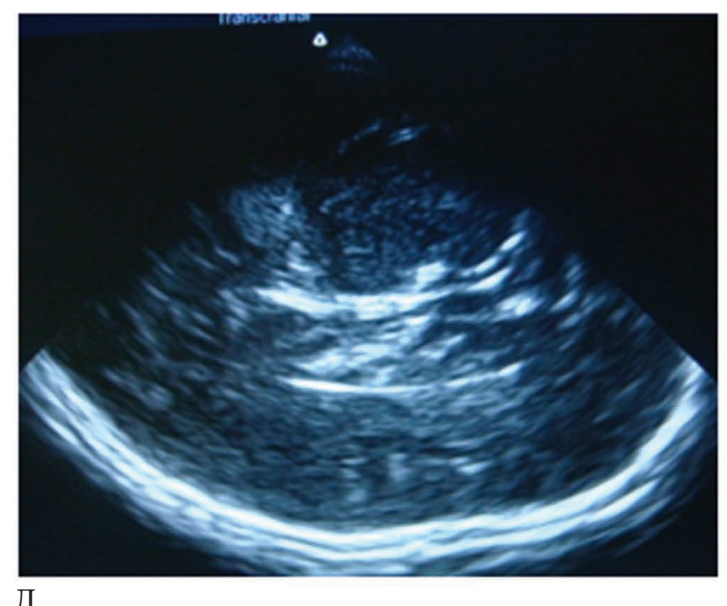

Д

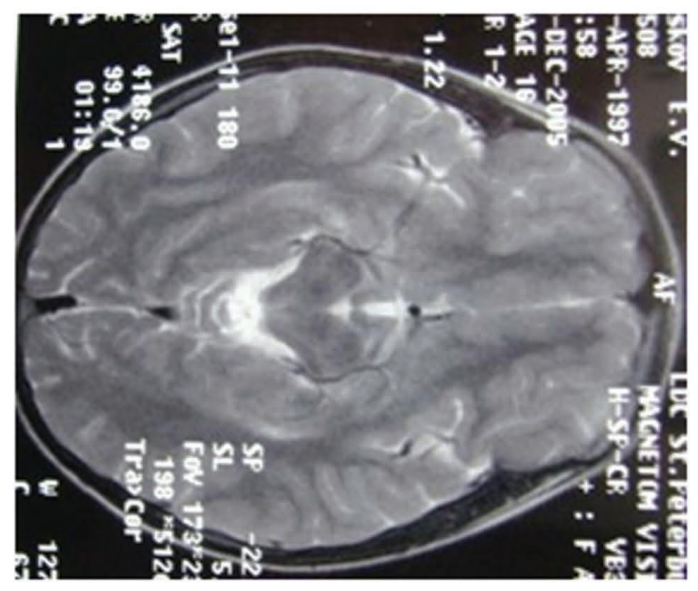

Б

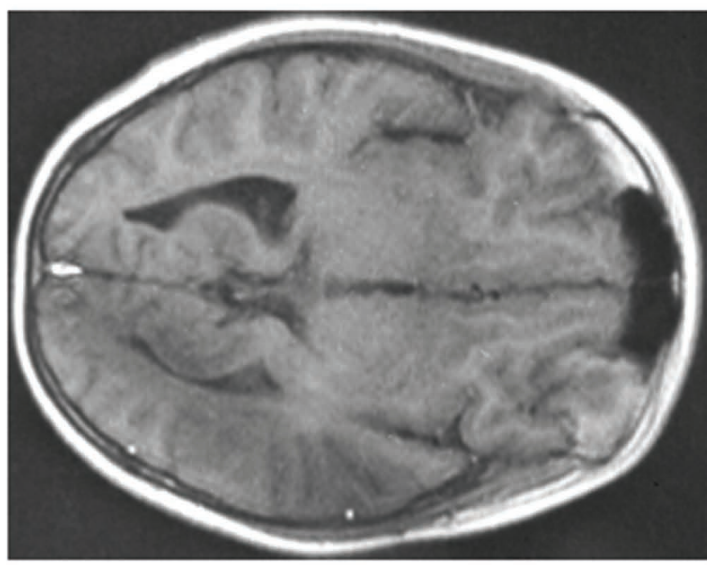

$\Gamma$

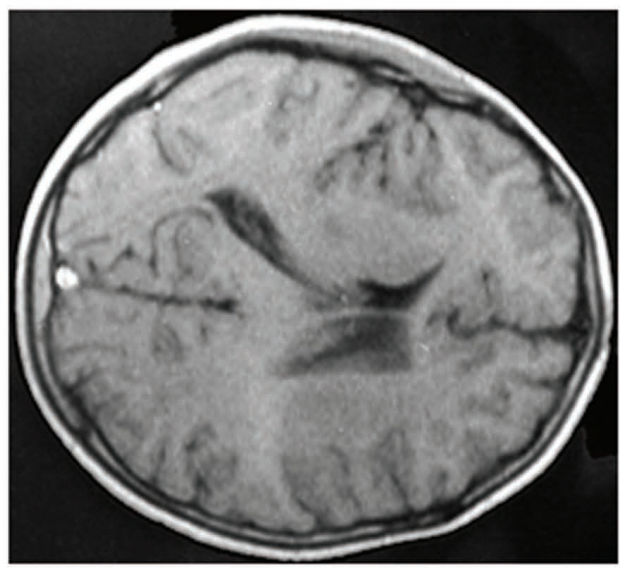

E

Рис. 4. Верификация элементов эхо-архитектоники стандартных плоскостей сканирования при кратком протоколе ТУС, А, В, Д - УС-изображение при сканировании в плоскостях $\mathrm{TH}_{0}, \mathrm{TH}_{1}, \mathrm{TH}_{2}$, Б, Г, Е - МРТ, проведенная в плоскостях, соответствующих $\mathrm{TH}_{0}, \mathrm{TH}_{1}, \mathrm{TH}_{2}$

Основной задачей ТУС при травме является поиск интракраниальных гематом (оболочечных, внутримозговых, внутрижелудочковых), очагов ушиба, дислокаций и отека головного мозга (табл. 3-5). Например, оболочные гематомы при ТУС проявляются наличием патологической зоны между костью и паренхимой мозга со стороны, противоположной датчику.
ТУС позволяет модернизировать существующие FAST-протоколы за счет обеспечения визуализации внутричерепного пространства (табл. 6). Методики проведения экстракраниальной УС являются общепринятыми и подробно описаны в литературе, поэтому они в настоящей работе не приводятся $[3,12-14,17,19,21,22,24-26]$. 
Таблица 3

УС-признаки острой эпидура^ьной гематомы

\begin{tabular}{|c|c|l|}
\hline УС-изображение & КТ-изображение & \multicolumn{1}{|c|}{ УС-признаки } \\
\hline & & $\begin{array}{l}\text { - двояковыпуклая зона повы- } \\
\text { шенной плотности, примыкаю- } \\
\text { щая к своду черепа } \\
\text { смещение срединных струк- } \\
\text { тур } \\
\text { < сужение бокового желудочка } \\
\text { на стороне гематомы }\end{array}$ \\
\hline
\end{tabular}

УС-признаки острой сублуральной гематомы

Таблица 4

\begin{tabular}{|c|c|c|}
\hline УС-изображение & КТ-изображение & УС-признаки \\
\hline & & $\begin{array}{l}\text { - серповидная зона повышен- } \\
\text { ной плотности, примыкающая } \\
\text { к своду черепа } \\
\text { - смещение срединных струк- } \\
\text { тур } \\
\text { - сужение бокового желудочка } \\
\text { на стороне гематомы }\end{array}$ \\
\hline
\end{tabular}

Таблица 5

УС-признаки острой внутримозговой гематомы

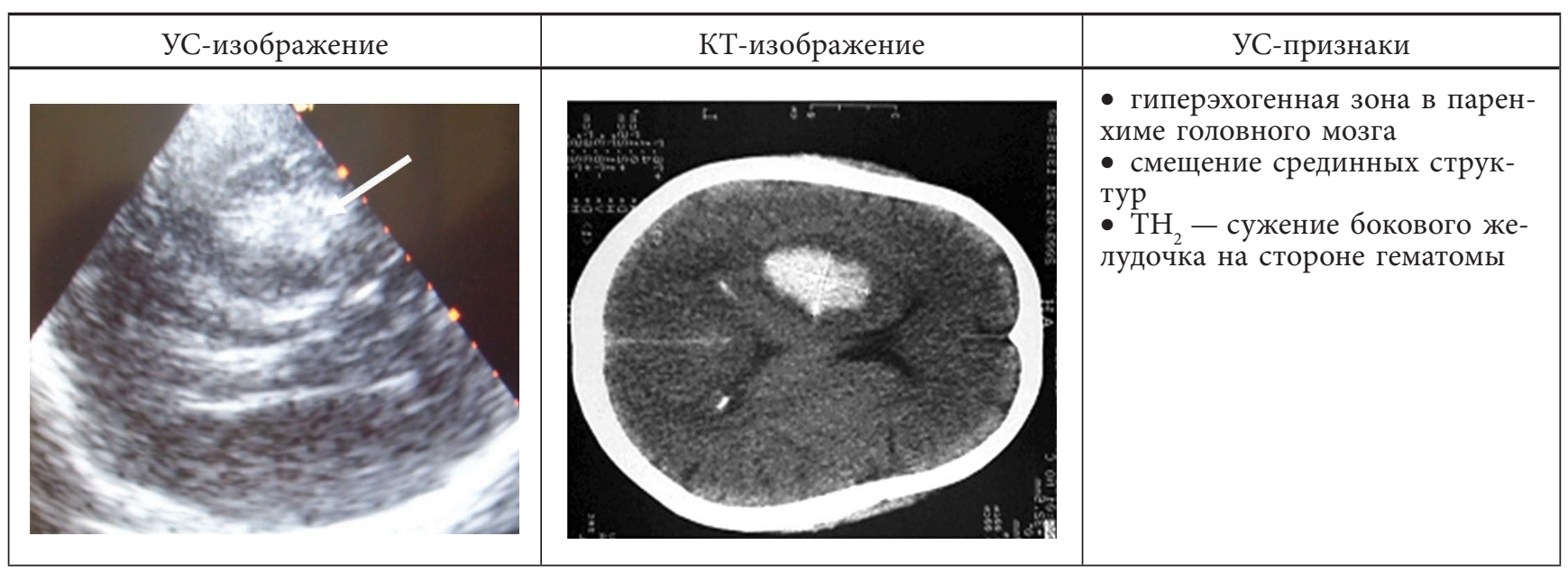


Модернизированный FAST-протокол

\begin{tabular}{|c|c|c|}
\hline Точки сканирования & Области сканирования & Задача \\
\hline & $\begin{array}{l}\text { Левая } \\
\text { височная }\end{array}$ & $\begin{array}{l}\text { Поиск компрессии среднего мозга, внутри- } \\
\text { мозговой и оболочечной гематом справа }\end{array}$ \\
\hline & Правая височная & $\begin{array}{l}\text { Поиск компрессии среднего мозга, внутри- } \\
\text { мозговой и оболочечной гематом слева }\end{array}$ \\
\hline & $\begin{array}{l}\text { Правый верхний ква- } \\
\text { дрант живота }\end{array}$ & $\begin{array}{l}\text { Поиск жидкости в гепаторенальном кармане } \\
\text { (кармане Морисона), вокруг печени, в правой } \\
\text { плевральной полости }\end{array}$ \\
\hline & $\begin{array}{l}\text { Левый верхний квадрант } \\
\text { живота }\end{array}$ & $\begin{array}{l}\text { Поиск жидкости в спленоренальном карма- } \\
\text { не, левом поддиафрагмальном пространстве, } \\
\text { в левой плевральной полости }\end{array}$ \\
\hline & Субкостальная область & Поиск жидкости в перикардиальной полости \\
\hline & Надлобковая область & Поиск жидкости в полости малого таза \\
\hline & $\begin{array}{l}\text { Верхняя часть грудной } \\
\text { клетки }\end{array}$ & Поиск пневмоторакса \\
\hline
\end{tabular}

\section{Показания к применению новых технологий}

А. На догоспитальном этапе (в пределах «золотого часа»)

1. Изолированная ЧМТ любой степени тяжести (показана ТУС).

1.1. При первичном осмотре (экспресс-диагностика).

1.2. На этапах эвакуации при минимальном ухудшении состояния (мониторинг).

2. Политравма (сочетанная ЧМТ) любой степени тяжести (показана ПС).

2.1. При первичном осмотре (экспресс-диагностика).

2.2. На этапах эвакуации при ухудшении состояния (мониторинг).

Б. В стационарах, не оснащенных аппаратами КТ (МРТ)

1. Изолированная ЧМТ любой степени тяжести (показана ТУС).

1.1. При поступлении в стационар (экспресс-диагностика).

1.2. Через 3 ч после травмы (мониторинг).

1.3. Через три дня после травмы (мониторинг).

1.4. При ухудшении состояния (мониторинг).

1.5. При отсутствии должной положительной динамики (мониторинг).

1.6. Перед транспортировкой в стационар, оснащенный КТ (МРТ).

1.7. Интраоперационная визуализация.

1.8. При оказании выездной помощи (экспресс-диагностика).
2. Сочетанная ЧМТ любой степени тяжести (показана ПС).

2.1. При поступлении в стационар (экспресс-диагностика).

2.2. Через 3 ч после травмы (мониторинг).

2.3. Через три дня после травмы (мониторинг).

2.4. При ухудшении состояния или отсутствии должной положительной динамики (мониторинг).

2.5. Перед транспортировкой в стационар, оснащенный КТ (МРТ).

2.6. При оказании выездной помощи специалистами данного стационара.

B. В стационарах, оснащенных аппаратами KT (MPT)

1. Необходимость нейровизуализации или визуализации «всего тела» у пациентов в реанимационном зале параллельно реанимационным мероприятиям (ПС) (первичная экспресс-диагностика).

2. Необходимость прикроватного минимально инвазивного интраскопического мониторинга (многократные исследования) при консервативном лечении внутричерепных гематом, для оценки эффективности лечения отека головного мозга, дислокационных синдромов, острой гидроцефалии (в том числе в послеоперационном периоде) (ТУС).

3. Легкая травма головы (все поступившие в приемное отделение стационара с ушибами мягких тканей головы, сотрясением головного мозга) (ТУС). 
4. После первичной КТ по поводу изолированной или сочетанной травмы головы необходимо провести повторное интраскопическое исследование головы через 3 ч и на 3-й день после травмы (даже при стабильном состоянии пациента или отсутствии признаков патологии головного мозга при первичном КТ-исследовании) (ТУС).

5. После первичной КТ, при минимальном ухудшении состояния или отсутствии должной положительной динамики (ТУС, ПС).

6. При необходимости уменьшить лучевую нагрузку на этапах лечения (ТУС, ПС).

7. При проведении тромболитической терапии по поводу внутричерепных гематом или ишемических повреждений (ТУС).

8. При «поломке» КТ-аппарата (ТУС, ПС).

9. При оказании выездной помощи специалистами данного стационара (ТУС, ПС).

10. Интраоперационная визуализация (ТУС, ПС).

11. Послеоперационный прикроватный мониторинг (ТУС, ПС).

Объем краниальных и экстракраниальных исследований на этапах оказания медицинской помощи (расширенный или краткий протоколы) выбирается на основании клинических данных и результатов первичных интраскопических исследований, например, рентгенографии, ТУС или ПС.

Абсолютных противопоказаний к применению ПС и ТУС нет. Относительные противопоказания - наличие пиодермии, открытой раны, свищей в области расположения ультразвукового датчика. В таких случаях необходимо перед исследованием поместить датчик в стерильный чехол (например, в стерильную хирургическую перчатку), предварительно смазав рабочую поверхность датчика ультразвуковым гелем. Зону исследования смазывают стерильным вазелином или стерильным ультразвуковым гелем.

Оптимальной для ПС является диагностическая ультразвуковая система, которая характеризуется: портативностью (вес не более 10 кг, что позволяет переносить ее в руках); автономным питанием; защитой от механических повреждений при транспортировке; возможностью архивирования исследования и его телетрансляции для анализа экспертом (при необходимости); обеспечением информационной поддержки для врача, оказывающего помощь пациентам с политравмой. Поэтому преимущество имеют портативные ультразвуковые системы, интегрированные с ноутбуком.

Учитывая перечисленные требования, создана специальная диагностическая система «Компас» (компьютерный мини-пансоноскоп), включающая в себя: а) миниатюрную ультразвуковую приставку к ноутбуку (Terason ECHO Ultrasound System, США, регистрационное удостоверение № ФЦЗ 2010/05993 с набором мультичастотных датчиков: секторный $4 \mathrm{~V} 2 \mathrm{~S}$ с фазированной решеткой, конвексный датчик 5C2A и линейный датчик $7 \mathrm{~L} 3-\mathrm{V})$; б) ноутбук с автономным питанием (процесcop Intel Core2 Duo, оперативная память 2 Гб, видеокарта с объемом памяти не менее 256 Мб, операционная система Windows XP, обязательно наличие FireWire connection или его аналогов); в) транспортный контейнер; в) пакет специальных программ.

Оптимальной моделью практического применения пансоноскопии является рациональное взаимодополняющее применение ключевых диагностических технологий медицинской визуализации (УС, КТ и МРТ) (поэтапная интраскопия). В табл. 7 приводятся основные этапы, цели и способы поэтапной интраскопии.

Таблица 7

Особенности поэтапной интраскопии (этапы, цели и способы визуализации)

\begin{tabular}{|c|c|c|}
\hline Этап & Цели & Способ \\
\hline $\begin{array}{l}\text { Интраскопический } \\
\text { скрининг }\end{array}$ & $\begin{array}{l}\text { 1. Доклиническое выявление опасных внутричерепных и внечерепных } \\
\text { повреждений путем массового обследования пациентов группы риска } \\
\text { (например, применение нейровизуализации у всех пациентов с легкой } \\
\text { травмой головы). } \\
\text { 2. Определение зон повышенного интереса. } \\
\text { 3. Выбор оптимального для данного пациента метода экспертной визуа- } \\
\text { лизации (КТ, МРТ, МРА и пр.). }\end{array}$ & $\mathrm{yC}$ \\
\hline $\begin{array}{l}\text { Интраскопическая } \\
\text { экспресс-диагностика }\end{array}$ & $\begin{array}{l}\text { 1. Максимально ранняя «прикроватная» диагностика опасных поврежде- } \\
\text { ний в условиях острого дефицита времени (например, в реанимационном } \\
\text { зале, параллельно с реанимационными мероприятиями). } \\
\text { 2. Выявление областей повышенного интереса. } \\
\text { 3. Выбор оптимального метода (методов) экспертной диагностики (КТ, МРТ, } \\
\text { МРА и пр.). }\end{array}$ & $\mathrm{yC}$ \\
\hline
\end{tabular}

- Ортопедия, травматология и восстановительная хирургия детского возраста. Том II. $\quad$ Выпуск $1 . \quad 2014$ ISSN $2309-3994$ 


\begin{tabular}{|c|c|c|}
\hline \multicolumn{3}{|c|}{ Продолжение табл. 7} \\
\hline Этап & Цели & Способ \\
\hline $\begin{array}{l}\text { Экспертная интра- } \\
\text { скопия }\end{array}$ & $\begin{array}{l}\text { 1. Максимально высокое качество визуализации обнаруженных при УС } \\
\text { изменений и уточнение состояния в зонах повышенного интереса, опре- } \\
\text { деленных на этапах скрининга и экспресс-диагностики. } \\
\text { 2. Выбор оптимального способа интраскопического мониторинга. }\end{array}$ & $\begin{array}{l}\text { KT } \\
\text { MPT } \\
\text { MPA }\end{array}$ \\
\hline $\begin{array}{l}\text { Интраскопический } \\
\text { мониторинг }\end{array}$ & $\begin{array}{l}\text { 1. Мини-инвазивный мониторинг изменений в области уточненных по- } \\
\text { вреждений или в зонах повышенного интереса на этапах лечения (в том } \\
\text { числе в послеоперационном периоде). } \\
\text { 2. Обеспечение «прикроватного» мониторинга. } \\
\text { 3. Экспертный мониторинг. }\end{array}$ & YC \\
\hline $\begin{array}{l}\text { Интраоперационная } \\
\text { интраскопия }\end{array}$ & $\begin{array}{l}\text { Интраскопическое сопровождение на этапах операции по поводу измене- } \\
\text { ний, выявленных на этапах диагностики }\end{array}$ & yc \\
\hline
\end{tabular}

\section{Общая оценка эфрфективности и перспектив новой технологии}

Эффективность и перспективы экстракраниальной УС хорошо изучены и подробно описаны в литературе [3, 12-14, 17, 19, $21,22,24-26]$. В настоящей работе внимание уделено инновационному компоненту ПС. Оценка эффективности ультразвуковой нейровизуализации осуществлялась путем сравнения результатов ТУС с данными традиционных методов (КТ, МРТ, операция, вскрытие и пр.). Результаты многолетних исследований представлены в серии работ $[4,6,7,11,16,18,20]$. Обобщенные данные в отношении детей $(n=2453$, от 1 дня жизни до 18 лет, средний возраст 6,6 \pm 0,14 года) и взрослых ( $n=273$, возраст от 18 до 85 лет, средний возраст $-42,2 \pm 18$ лет) представлены в специальных исследованиях $[18,20]$. У детей эффективность УС при визуализации структурных внутричерепных изменений в амбулаторной клинической группе составляет 97,6 \%, при легкой черепно-мозговой травме - $93 \%$, а при жизнеугрожающих состояниях (дислокационных синдромах и отеке головного мозга) - 90,3\%. У взрослых пациентов при гидроцефалии, супратенториальных опухолях и кистах эффективность ТУС достигает соответственно 100, 82 и $80 \%$ случаев. Наиболее эффективной ТУС является у женщин в возрасте до 40 лет. Однако и у пациентов более старшего возраста в подавляющем большинстве случаев ТУС обеспечивает «осмотр» ключевых внутричерепных объектов, имеющих наиболее важное значение для ранней диагностики и мониторинга «опасных» СВИ (внутричерепных гематом, опухолей, кист, гидроцефалии, отека и дислокаций головного мозга). Например, третий желудочек, боковые желудочки, средний мозг визуализируются соответственно в 90, 91 и $83 \%$. Только у 10 \% обследуемых визуализация была недостаточной из-за высокой ультразвуковой плотности височной кости.

Технология ТУС может быть недостаточно эффективной по субъективным и объективным причинам. Субъективные причины уровень подготовки врача и нарушение технологии обследования. Объективные - плохое ультразвуковое окно, недостаточный контакт между кожей и датчиком, ультразвуковые артефакты при сканировании, применение оборудования, которое не прошло тестирования на его применение для ТУС. В последние годы появляется все большее количество новых ультразвуковых аппаратов, мультичастотных датчиков и специальных программ, повышающих эффективность их применения для ПС.

ПС имеет достаточно широкие показания для применения на всех этапах оказания медицинской помощи пациентам с сочетанной ЧМТ и политравмой (в том числе и в условиях травмоцентров 1-го уровня). ПС предназначена в основном для тех случаев, когда применение КТ или МРТ невозможно, невыгодно или связано с повышенным риском осложнений (например, транспортировки, даже в условиях стационара). Предложенная технология имеет особое значение в медицине катастроф, экстремальной медицине, медицине чрезвычайных ситуаций и пр. ПС безальтернативна для модернизации медицинской помощи, оказываемой аэромобильными медицинскими группами. Велика роль ПС не только на этапе сортировки и первичной диагностики при политравме, но и при мониторинге выявленных изменений во время транспортировки пострадавших и оказания медицинской помощи на остальных этапах, в том числе в условиях специализированных центров травмы. 


\section{Выводы}

1. Технологии «ультрасонографии всего тела» и «FAST-протокол» приобретают все большее значение в практической медицине.

2. Принципиальным недостатком современных вариантов «ультрасонографии всего тела» и «FAST-протокола» является невозможность визуализации внутричерепных изменений, которые относятся к наиболее частым и наиболее опасным повреждениям при политравме.

3. Разработка транскраниальной ультрасонографии позволяет модернизировать «ультрасонографию всего тела» и «FAST-протокол», обеспечивая возможность визуализации внутричерепного пространства.

4. Пансоноскопия является инновационным вариантом «FAST-протокола» и «ультрасонографии всего тела».

5. Применение мини-комплексов, сочетающих в себе возможности пансоноскопии и информационно-телекоммуникационных технологий, создает условия для совершенствования медицинской помощи детям и взрослым при политравме.

\section{Аитература}

1. Анкин Л. Н., Анкин Н. Л. Практическая травматология. Европейские стандарты лечения. М.: Книга плюс, 2002. 480 с.

2. Анкин Л. Н. Политравма (организационные, тактические и методологические проблемы). М.: МЕДпресс-информ, 2004. 176 с.

3. Васильев А. Ю., Ольхова Е. Б. Ультразвуковая диагностика в неотложной детской практике: руководство для врачей. М.: ГЭОТАР-Медиа, 2010. 832 с.

4. Иова А. С,. Лихтерман Л. Б., Гармашов Ю. А. Ультразвуковые методы диагностики черепно-мозговой травмы// Черепно-мозговая травма. Клиническое руководство/ под ред. А. Н. Коновалова, Л. Б. Лихтермана, А. А. Потапова. Т. 1. Глава 13. М., 1998. C. 395-406.

5. Иова А. С., Гармашов Ю. А. Способ диагностики заболеваний головного мозга// Патент Российской Федерации на изобретение № 2125401 (Зарегистрирован в Государственном реестре изобретений РФ 27 января 1999 г.).

6. Иова А. С., Гармашов Ю. А. Транскраниальная ультрасонография: Метод. рекомендации / СЗГМУ им. И. И. Мечникова. СПб., 2002. 24 с.

7. Иова А. С., Крюкова И. А., Гармашов Ю. А., Крюков Е. Ю. Транскраниальная ультрасонография (краткий и расширенный протокол): Учеб. пособие / СЗГМУ им. И. И. Мечникова. СПб., 2012. 37 с.
8. Иова А. С., Крюкова И. А. Пансоноскопия в условиях неотложной медицины (новая медицинская технология) // Государственный реестр новых медицинских технологий (ФС № 2011/085). 2011.

9. Иова А. С., Крюкова И. А., Иова Д. А. Пансоноскопия при политравме (модернизация ультрасонографии «всего тела» и FAST-протокола): Учеб. пособие/СЗГМУ им. И. И. Мечникова. СПб., 2013. 56 с.

10. Корниенко В. Н., Пронин И. Н. Диагностическая нейрорадиология. М., 2006. 1327 с.

11. Мидленко А. И. Региональная модель оказания медицинской помощи детям с черепно-мозговой травмой: Автореф. дис. ... д-ра мед. наук. СПб., 2005. 42 c.

12. О. Дж. Ма, Дж. Р. Матиэр. Ультразвуковое исследование в неотложной медицине. М.: Бином, 2007. 390 c.

13. Ольхова Е. Б., Быковский В. А., Романов Д. В. Значение комплексного УЗИ в диагностике травматических повреждений у детей раннего возраста// Эхография. 2001. № 2 (1). С. 54-66.

14. Практическое руководство по ультразвуковой диагностике. Общая ультразвуковая диагностика/под ред. В. В. Митькова. М.: Издательский дом «Видар», 2003. 720 c.

15. Трофимова Т. Н., Ананьева Н. И., Назинкина Ю. В. и др. Нейрорадиология. СПб.: Изд. дом СПбМАПО, 2005. 288 c.

16. Ультрасонография в нейропедиатрии (новые возможности и перспективы). Ультрасонографический атлас / А. С. Иова, Ю. А. Гармашов, Н. В. Андрущенко, Т. С. Паутницкая. СПб.: Петровский и Кㅇ, 1997. $160 \mathrm{c}$.

17. Ультразвуковые исследования костно-мышечной системы: Практическое руководство/ Пер. с англ. А. Н. Хитровой; под ред. Г. И. Назаренко, И. Б. Героевой. М.: Издательский дом «Видар», 2007. $400 \mathrm{c}$.

18. Шапарюк С. И. Клиническое значение транскраниальной ультрасонографии в диагностике структурных внутричерепных изменений у взрослых: Автореф. дис. ... канд. мед. наук. СПб., 2008. 25 с.

19. Шахов Б. Е., Сафонов Д. В. Трансторакальное ультразвуковое исследование легких и плевры. Н. Новгород: Морской Петербург, 2002. 118 с.

20. Щугарева Л. М. Оптимизация диагностики заболеваний головного мозга у детей в условиях многопрофильной детской больницы (системный подход): Автореф. дис. ... д-ра мед. наук. СПб., 2013. 43 с.

21. Christie-Large M., Michaelides D. Focused assessment with sonography for trauma: the FAST scan//Trauma. 2008. Vol. 10, № 2. P. 93-101.

22. Gorb Yuliya. Ургентная сонография при травме (Fast protocol). 2009. (sonomir.wordpress.com).

23. Kristensen J. K., Buemann B., Keuhl E. Ultrasonic scanning in the diagnosis of splenic haematomas// Acta Chir Scand. 1971. Vol. 137. P. 653-7. 
24. Kirkpatrick A. W., Sirois M., Laupland K. B. [et al.] Hand-held thoracic sonography for detecting post-traumatic pneumothoraces: the Extended Focused Assessment with Sonography for Trauma (EFAST) // J. Trauma. 2004. Vol. 57. P. 288-295.

25. Lichtenstein D. A. Whole Body Ultrasonography in the Critically ill. Paris; France. 2010. 326 p.
26. Rozycki G. S., Ochsner M. G., Schmidt J. A. [et al.] A prospective study of surgeon-performed ultrasound as the primary adjuvant modality for injured patient assessment//Trauma. 1995. Vol. 39. № 3. P. 492-498.

\title{
PANSONOSCOPY IN POLYTRAUMA (NEW MEDICAL TECHNOLOGY)
}

\author{
Iova A. S., Krukova I. A., Iova D. A.
}

\section{North-Western State Medical University n. a. I. I. Mechnikov, St.-Petersburg}

$\diamond$ This article deals with the actual problem of present-day traumotology - improvement of rendering of medical care for patients with polytrauma. The new technology "Pansonoscopy" is presented, which is the minimally invasive and widely available method of fast imaging of the "whole body" of the patient in any medical situations. It permits to detect the most frequent and dangerous traumatic injuries (cranial, thoracal, abdominal, skeletal, etc.) applying portable ultrasound scanners in real-time mode. The guarantee of imaging of the intracranial injuries, pos- sibility realization of ultrasound examination by clinician on his own, and possibility of online medical consultations to experts (sonologist) are fundamently new. This technology is destined for the large sections of practitioners, what render medical care for patients with polytrauma.

Key words: transcranial ultrasound, emergency ultrasound, "whole body" ultrasonography, pansonoscopy, polytrauma, concomitant head injury in children and adults, FAST - protocol.
Иова Александр Сергеевич - д. м. н., профессор, нейрохирург, врач ультразвуковой диагностики, заведующий кафедрой детской невропатологии и нейрохирургии ГБОУ ВПО «СЗГМУ им. И. И. Мечникова», ведущий научный сотрудник ФГБУ «НИДОИ им. Г. И. Турнера» Минздрава России. 191015, СПб, ул. Кирочная, 41. Еmail: a_iova@mail.ru

Крюкова Ирина Александровна - к. м. н., невролог, врач ультразвуковой диагностики, ассистент кафедры детской травматологии и ортопедии ГБОУ ВПО «СЗГМУ им. И. И. Мечникова». 191015, СПб, ул. Кирочная, 41. E-mail: i_krukova@mail.ru

Иова Дмитрий Александрович - нейрохирург, врач ультразвуковой диагностики, младший научный сотрудник научно-исследовательской лаборатории «Инновационные технологии медицинской навигации» ГБОУ ВПО «СЗГМУ им. И. И. Мечникова». 191015, СПб, ул. Кирочная, 41. E-mail: iova@rnova.ru
Iova Alexandr Sergeevich - MD, DMedSc, neurosurgeon, sonologist, doctor of medical science, professor, head of the department of pediatric neurology and neurosurgery at St.-Petersburg North-Western State Medical University n. a. I. I. Mechnikov. St.-Petersburg, 191015, Kirochnaya str., 41. E-mail: a_iova@mail.ru

Krukova Irina Alexandrovna - MD, DMedSc, neurologist, sonologist, $\mathrm{PhD}$, assistent of department of pediatric trauma and orthopedics at St.-Petersburg North-Western State Medical University n. a. I. I. Mechnikov. St.-Petersburg, 191015, Kirochnaya str., 41. E-mail: i_krukova@mail.ru

Iova Dmitriy Alexandrovich - MD, neurosurgeon, sonologist, junior researcher at the Research Laboratory "Innovative technologies of medical navigation" at NorthWestern State Medical University n. a. I. I. Mechnikov. St.-Petersburg, 191015, Kirochnaya str., 41. E-mail: iova@ rnova.ru. 